Article

\title{
Strain-Dependent Impact of G and SH Deletions Provide New Insights for Live-Attenuated HMPV Vaccine Development
}

\author{
Julia Dubois ${ }^{1,2, *(\mathbb{C})}$, Andrés Pizzorno ${ }^{1}\left(\mathbb{D}\right.$, Marie-Hélène Cavanagh ${ }^{2}$, Blandine Padey ${ }^{1}{ }^{(}$, \\ Claire Nicolas de Lamballerie ${ }^{1}{ }^{(}$, Olus Uyar $^{2}{ }^{(D}$, Marie-Christine Venable ${ }^{2}$, Julie Carbonneau ${ }^{2}(\mathbb{D}$, \\ Aurélien Traversier ${ }^{1}$, Thomas Julien ${ }^{1,3}$, Sophie Lavigne ${ }^{4}$, Christian Couture ${ }^{4}$, Bruno Lina ${ }^{1,5}{ }^{(}$, \\ Marie-Ève Hamelin ${ }^{2}$, Olivier Terrier ${ }^{1}{ }^{1}$, Manuel Rosa-Calatrava ${ }^{1,3, *, \dagger}$ and Guy Boivin ${ }^{2,+}$ \\ 1 Laboratoire de Virologie et Pathologie Humaine-VirPath team, Centre International de Recherche en \\ Infectiologie (CIRI), INSERM U1111, CNRS UMR5308, ENS Lyon, Université Claude Bernard Lyon 1, \\ Université de Lyon, 69008 Lyon, France; mario-andres.pizzorno@univ-lyon1.fr (A.P.); \\ blandine.padey@univ-lyon1.fr (B.P.); claire.nicolas-de-lamballerie@univ-lyon1.fr (C.N.d.L.); \\ aurelien.traversier@univ-lyon1.fr (A.T.); bruno.lina@univ-lyon1.fr (B.L.); olivier.terrier@univ-lyon1.fr (O.T.) \\ 2 Centre de Recherche en Infectiologie of the Centre Hospitalier Universitaire de Québec and Université Laval, \\ QC G1V 4G2, Canada; marie-helene.cavanagh@crchudequebec.ulaval.ca (M.-H.C.); \\ olus.uyar@crchudequebec.ulaval.ca (O.U.); marie-christine.venable@crchudequebec.ulaval.ca (M.-C.V.); \\ julie.carbonneau@crchudequebec.ulaval.ca (J.C.); marie-eve.hamelin@crchudequebec.ulaval.ca (M.-È.H.); \\ guy.boivin@crchudequebec.ulaval.ca (G.B.) \\ 3 VirNext, Faculté de Médecine RTH Laennec, Université Claude Bernard Lyon 1, Université de Lyon, 69008 \\ Lyon, France; thomas.julien@univ-lyon1.fr \\ 4 Quebec Heart and Lung Institute, Laval University, Quebec City, QC G1V 4G5, Canada; \\ sophlavigne@hotmail.com (S.L.); christian.couture@ssss.gouv.qc.ca (C.C.) \\ 5 Laboratoire de Virologie, Centre National de Référence des virus Influenza, Institut des Agents Infectieux, \\ Groupement Hospitalier Nord, Hospices Civils de Lyon, 69004 Lyon, France \\ * Correspondence: julia.dubois@univ-lyon1.fr (J.D.); manuel.rosa-calatrava@univ-lyon1.fr (M.R.-C.); \\ Tel.: +33-4-78-771-099 (J.D. \& M.R.-C.) \\ $+\quad$ M.-R.C. and G.B. are co-last authors.
}

Received: 2 October 2019; Accepted: 23 October 2019; Published: 30 October 2019

\begin{abstract}
Human metapneumovirus (HMPV) is a major pediatric respiratory pathogen with currently no specific treatment or licensed vaccine. Different strategies to prevent this infection have been evaluated, including live-attenuated vaccines (LAV) based on SH and/or G protein deletions. This approach showed promising outcomes but has not been evaluated further using different viral strains. In that regard, we previously showed that different HMPV strains harbor distinct in vitro fusogenic and in vivo pathogenic phenotypes, possibly influencing the selection of vaccine strains. In this study, we investigated the putative contribution of the low conserved SH or G accessory proteins in such strain-dependent phenotypes and generated recombinant wild type (WT) and SH- or G-deleted viruses derived from two different patient-derived HMPV strains, A1/C-85473 and B2/CAN98-75. The $\Delta \mathrm{SH}$ and $\Delta \mathrm{G}$ deletions led to different strain-specific phenotypes in both LLC-MK2 cell and reconstituted human airway epithelium models. More interestingly, the $\Delta \mathrm{G}-85473$ and especially $\triangle \mathrm{SH}-\mathrm{C}-85473$ recombinant viruses conferred significant protection against HMPV challenge and induced immunogenicity against a heterologous strain. In conclusion, our results show that the viral genetic backbone should be considered in the design of live-attenuated HMPV vaccines, and that a SH-deleted virus based on the A1/C-85473 HMPV strain could be a promising LAV candidate as it is both attenuated and protective in mice while being efficiently produced in a cell-based system.
\end{abstract}


Keywords: human metapneumovirus (HMPV); live-attenuated vaccine (LAV); G protein; SH protein; gene deletion; reverse genetics

\section{Introduction}

Human metapneumovirus (HMPV) is a worldwide cause of acute respiratory tract infections (ARTI) among children, the elderly and immunocompromised individuals [1,2]. HMPV infections share many features with those of the human respiratory syncytial virus (HRSV), also belonging to the Pneumoviridae family [3,4]. Despite the important clinical burden in infants and young children, no licensed vaccine or specific and potent antiviral are currently available. While several HRSV vaccine candidates have already entered clinical trials [5], some HMPV candidates have shown the potential to progress towards clinical evaluation stages [6]. In that regard, different HMPV vaccine strategies have been evaluated in animals, from formalin-inactivated vaccine, leading to enhanced disease [7], to the elaboration of protein-based recombinant vaccines or live-attenuated vaccines (LAV) [6]. Among them, LAV have shown the potential to elicit both humoral and mucosal immunity and mimic natural viral replication routes, and they are therefore considered as highly suitable for HMPV pediatric immunization strategies [8].

HMPV viruses are divided into two main phylogenetic lineages (A and B), which are further divided into at least two sub-lineages (A1, A2a/A2b, B1 and B2) [9-13]. The HMPV genome is composed of a negative single stranded RNA molecule of approximately $13 \mathrm{~kb}$ in length, containing eight genes encoding for nine different proteins [14,15], including three surface glycoproteins (F, G, SH). The F (fusion) glycoprotein is the major HMPV antigen [16] and leads to both attachment and fusion of viral particles to the target cell [17]. In contrast, the exact role of G (glycoprotein) and SH (small hydrophobic) glycoproteins is still a matter of debate. Indeed, the F protein of HMPV has been shown to bind not only the cellular integrin $\alpha \mathrm{V} \beta 1$ receptor but also glycosaminoglycans (GAGs), such as heparan sulfate, hence being able to substitute to the virus GAG-mediated attachment function once exclusively attributed to the $G$ protein [18-21]. Nonetheless, a role of the $G$ protein was also suggested in the host cell response to infection [22-24]. For instance, stimulation of the retinoid-acid inducible gene 1 (RIG-I) signaling pathway was reported with a recombinant HMPV (rHMPV) lacking the G protein $(\Delta G)$ in vitro, which leads to increased NF- $\kappa B$ activation and enhanced cytokine secretion [22]. On the other hand, the SH protein has been shown to alter the NF- $\mathrm{B}$ pathway [25] and also to form a viroporin complex at the cell membrane [26].

The $\mathrm{G}$ and SH proteins have been considered for a long time as "accessory" non-essential proteins for HMPV replication [27], as illustrated by recombinant HMPV viruses lacking either G, SH or both genes that can replicate efficiently in vitro and in vivo [28]. Moreover, the contribution of $\mathrm{G}$ and $\mathrm{SH}$ proteins to HMPV antigenicity, as well as the attenuation phenotype associated to G-deleted virus, led to the consideration of such modified viruses as potential LAV candidates [16,27]. However, the achievement of such perspectives is nuanced by the fact that all previous studies were based on a unique HMPV backbone, notably the prototypical CAN97-83 strain from the A2 sub-lineage. In that regard, many HMPV subtypes co-circulate each year with high genetic diversity among A and B subtypes, particularly in the case of the less conserved $\mathrm{G}$ and SH proteins, with approximately $37 \%$ and $59 \%$ amino acid sequence homologies between subtypes, respectively $[9,14]$. In parallel, we and others previously demonstrated that HMPV viruses diverge in their in vitro and/or in vivo phenotypes in a strain-dependent manner, notably by considering the HMPV F and G proteins and their functions [18,29-33].

In this context, we generated recombinant wild type (WT) and SH- or G-deleted viruses $(\Delta \mathrm{SH}$ and $\Delta \mathrm{G}$ respectively) from two patient-derived HMPV strains (A1/C-85473 and B2/CAN98-75) and compared the respective functional impacts of $\mathrm{SH}$ and $\mathrm{G}$ deletions. In this context, we observed different strain-specific phenotypes both in LLC-MK2 cells and reconstituted human airway epithelium 
(HAE) models that provided new insights on the importance of the genetic background in the design of HMPV LAV. This prompted us to evaluate the $\Delta \mathrm{SH}-\mathrm{C}-85473$ and $\Delta \mathrm{G}-\mathrm{C}-85473$ recombinant viruses in BALB/c mice for their capacity to induce efficiently neutralizing antibody response, recruit immune cells in lungs and protect mice against lethal HMPV challenge. Our results suggest that an HMPV C-85473 strain-based LAV harboring SH and/or G deletions would be a promising platform for further development of pneumovirus vaccine candidates.

\section{Materials and Methods}

\subsection{Cells}

LLC-MK2 cells (ATCC CCL-7) were maintained in minimal essential medium (MEM, Life Technologies, Carlsbad, CA, USA) supplemented with 10\% fetal bovine serum (FBS, Wisent) and 10 mM HEPES (Sigma-Aldrich, St. Louis, MO, USA). BSR-T7/5 cells (a kind gift from Dr Ursula Buchholz at the National Institute of Allergy and Infectious Diseases in Bethesda, MD) were cultured in MEM supplemented with 10\% FBS, 1\% non-essential amino acids (NEAA) (Life Technologies), $10 \mathrm{mM}$ HEPES (Sigma-Aldrich), 1\% penicillin/streptomycin (Wisent) and $0.2 \mathrm{mg} / \mathrm{mL}$ geneticin (G418, Life Technologies).

\subsection{Rescue of Recombinant Viruses}

pSP72 plasmids (Promega, Madison, WI, USA) encoding the full-length genomic cDNA of HMPV B2/CAN98-75 or A1/C-85473 strains (GenBank accession numbers: AY145289.1 and KM408076.1, respectively) were constructed as previously described [29,34]. To generate G- or SH-deleted viruses, plasmids encoding HMPV antigenomes were amplified with Phusion DNA polymerase (New England Biolabs, Ipswich, MA, USA) using primers (listed in Table 1) designed to match with the $3^{\prime}$ and $5^{\prime}$ regions of either $\mathrm{G}$ or $\mathrm{SH}$ genes, and taking care to conserve an intergenic sequence between flanking genes (as represented in Figure 1A). After amplification, linear DNA was phosphorylated and re-ligated by T4 Ligase. All plasmids were sequenced completely.

BSR-T7 cells were transfected with the HMPV antigenome constructions plus four supporting plasmids, encoding N, P, L, and M2-1 ORFs of CAN98-75 and LLC-MK2 cells were added for co-culture (two to three days), as previously described [29]. Cells were harvested, sonicated, centrifuged and the supernatant was diluted to inoculate LLC-MK2 monolayers. After three to four amplification passages onto LLC-MK2 cells, recombinant GFP-expressing viruses (rHMPV) were concentrated by ultracentrifugation, resuspended in OptiMEM (Life Technologies) and stored at $-80{ }^{\circ} \mathrm{C}$. Viral stocks were titrated as 50\% tissue culture infectious doses $\left(\mathrm{TCID}_{50}\right) / \mathrm{mL}$ [35].

Table 1. List of primers.

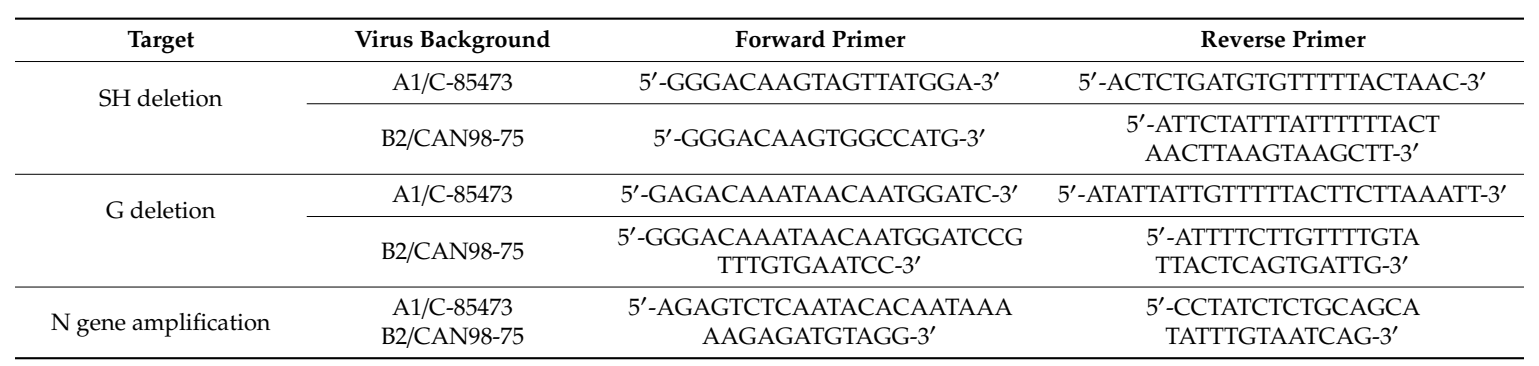


A

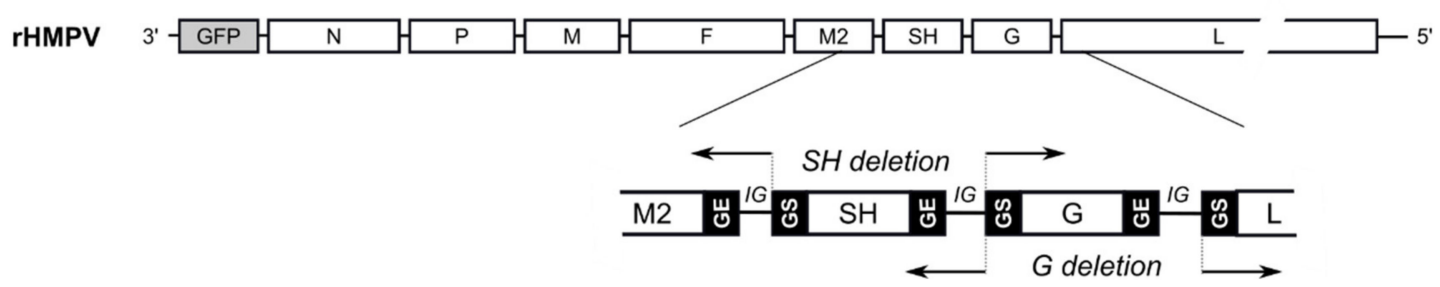

B

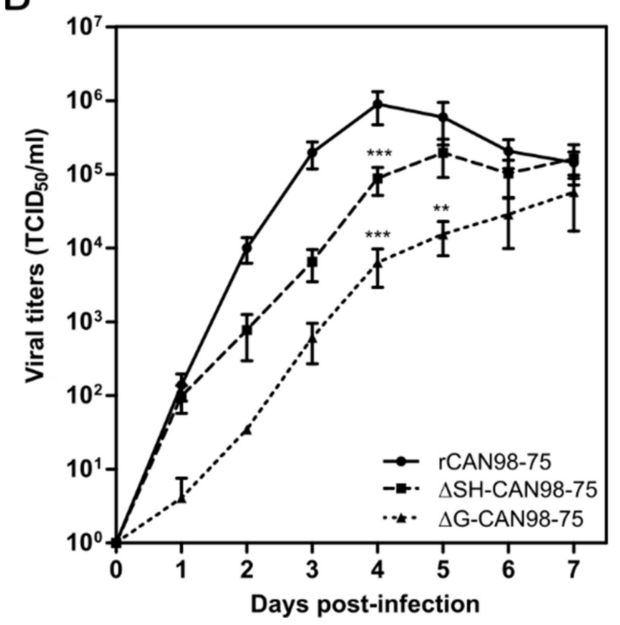

C

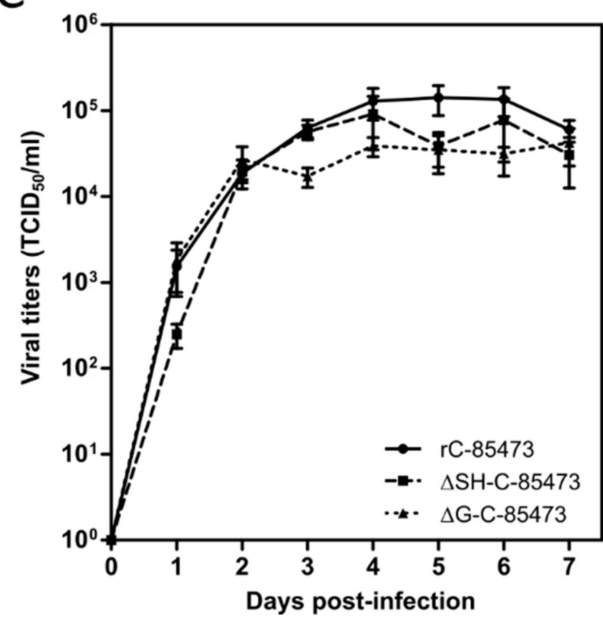

D

rCAN98-75

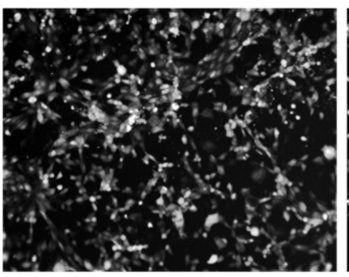

rC-85473

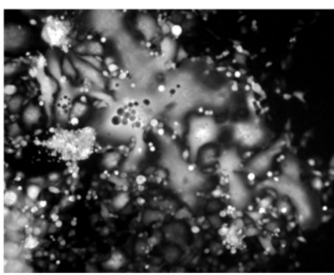

$\triangle$ SH-CAN98-75

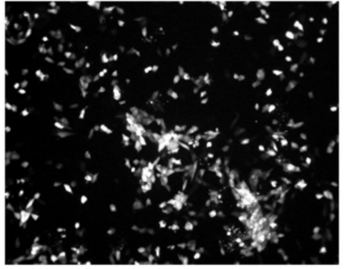

$\Delta \mathrm{SH}-\mathrm{C}-85473$

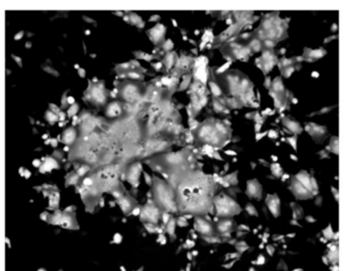

$\Delta G-C A N 98-75$

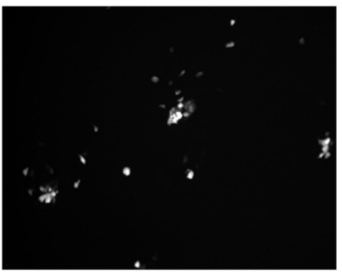

$\Delta \mathrm{G}-\mathrm{C}-85473$

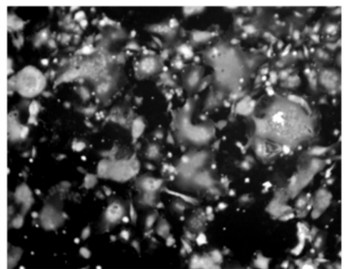

Figure 1. Construction of recombinant human metapneumovirus (HMPV) viruses and in vitro replicative capacity of SH and G-deleted rHMPV viruses. (A) Schematic representation of the genome of a recombinant GFP-expressing recombinant HMPV (rHMPV) viruses, with specific focus on the region of the genome describing the position of primers used for the deletion strategy (arrow, Table 1). GS: gene start. GE: gene end. IG: intergenic sequence. (B,C) LLC-MK2 monolayers in 24 wells-plates were infected with each of the six recovered rHMPV strains (rCAN98-75, $\triangle$ SH-CAN98-75, $\triangle$ G-CAN98-75; rC-85473, $\Delta$ SH-C-85473, $\Delta$ G-C-85473) at a MOI of 0.01 . Supernatants were harvested every $24 \mathrm{~h}$ for seven days, frozen, sonicated and titrated as tissue culture infectious doses $\left(\mathrm{TCID}_{50}\right) / \mathrm{mL}$ on LLC-MK2 cells. Growth curves represent mean titers of two independent experiments, with each time point titrated in triplicate. ${ }^{* *} p<0.01,{ }^{* * *} p<0.001$ when comparing each $\Delta \mathrm{SH} / \Delta \mathrm{G}$ virus to its wild type (WT) counterpart using repeated measures two-way ANOVA. (D) Images of representative cytopathic effects and spread of each virus at three days post-infection were captured using fluorescent microscopy $(10 \times$ magnification $)$. 


\subsection{In Vitro Experiments}

For replication kinetics assays, confluent monolayers of LLC-MK2 cells in 24-wells plates were infected with rHMPV viruses at a Multiplicity of Infection (MOI) of 0.01, as described previously [29]. Supernatants of infected wells were harvested in triplicate every $24 \mathrm{~h}$ for seven days and end-point $\mathrm{TCID}_{50} / \mathrm{mL}$ titrations were performed on each sample.

For viral binding assays, confluent LLC-MK2 monolayers were washed with cold PBS and placed on ice before rHMPV inoculation at MOI 0.5. After adsorption times on ice (30 min, 1, 2 or $3 \mathrm{~h}$ ), the inoculum was removed and replaced by fresh infection medium. After a $24 \mathrm{~h}$ incubation at $37^{\circ} \mathrm{C}$ and $5 \% \mathrm{CO}_{2}$, cells were trypsinized, centrifuged and fixed using $2 \%$ formaldehyde. The percentages of infected GFP positive cells over $1 \times 10^{4}$ total cells were measured by flow cytometry by using a FACSCantoII analyzer (Becton Dickinson, Franklin lakes, NJ, USA) with FACSDiva software. Data were analyzed by using the FlowJo software (Tree Star, Inc., Ashland, OR, USA) and normalized to each virus inoculum.

For experimental virus entry assays, confluent LLC-MK2 cells were inoculated at a MOI of 0.5 after being placed on ice for $5 \mathrm{~min}$ and washed with cold PBS. The binding of virus to cells proceeded for $2 \mathrm{~h}$ on ice until the inoculum was replaced by fresh infection medium. Cells were incubated for $5 \mathrm{~min}, 30 \mathrm{~min}, 1$ or $2 \mathrm{~h}$ at $37^{\circ} \mathrm{C}$ and $5 \% \mathrm{CO}_{2}$ to allow virus entry into cells, medium was then removed and citrate buffer $(40 \mathrm{mM}$ sodium citrate dihydrate, $10 \mathrm{mM}$ potassium chloride, $135 \mathrm{mM}$ sodium chloride, $\mathrm{pH}$ 3.0) was added to inactivate any remaining extracellular virus, as previously described [36]. Cells were washed in PBS and incubated at $37^{\circ} \mathrm{C}$ in fresh medium during $24 \mathrm{~h}$. Infected cells were quantified by GFP detection in flow cytometry and values were normalized to condition without viral inactivation.

\subsection{Infection of Reconstituted Human Airway Epithelium}

In vitro 3D reconstituted human airway epithelium (HAE), derived from a pool of healthy donors' primary bronchial cells (MucilAir ${ }^{\mathrm{TM}}$ ) were purchased from Epithelix (Genève, Switzerland). A viral inoculum corresponding to a MOI of 0.1 was added onto $\mathrm{HAE}$ and incubated for $1.5 \mathrm{~h}$ at $37^{\circ} \mathrm{C}$ and $5 \%$ $\mathrm{CO}_{2}$. After five days of infection, captured images of infected HAE by fluorescent microscopy were taken and the whole epithelium was scraped in RLT buffer (Qiagen, Hilden, Germany). Total RNA was then extracted with RNeasy minikit (Qiagen) to perform viral genome quantification by RT-qPCR.

\subsection{Real-Time (RT)-PCR}

The total RNA extracted from samples was randomly reverse transcribed using SuperScriptII RT (Invitrogen, Carlsbad, CA, USA) at $42{ }^{\circ} \mathrm{C}$. Amplification of the HMPV $N$ gene was performed by quantitative PCR using SYBR Green qPCR Master Mix (Agilent, Santa Clara, CA, USA) and a set of primers listed in Table 1. The calibration of HMPV $N$ copies was assessed by amplification of a plasmid kindly provided by Dr Ab Osterhaus (Erasmus Medical Center, Rotterdam, The Netherlands).

\subsection{Animal Studies}

Four- to six-week-old BALB/c mice (Charles River Laboratories, Wilmington, MA, USA), housed in groups of five per micro-isolator cage, were infected intra-nasally with $5 \times 10^{5} \mathrm{TCID}_{50}$ of rHMPV C-85473 viruses (WT, $\Delta S H$ or $\Delta \mathrm{G}$ ). As a control group, mice were mock-infected intra-nasally with OptiMEM. Animals were monitored on a daily basis during 14 days for weight loss, clinical signs, reduced activity or ruffled fur and were sacrificed if they reached $20 \%$ of initial weight loss. Mice were euthanized at 5 days post-infection (dpi) using sodium pentobarbital and lungs were removed for the evaluation of viral titers or histopathological analysis, as described [29]. For virus titration, lungs were homogenized in $1 \mathrm{~mL}$ of PBS before TCID $_{50}$ titration or $N$ quantification by RT-qPCR.

For HMPV challenge experiments three weeks post-immunization with $5 \times 10^{5} \mathrm{TCID}_{50}$ of recombinant $\mathrm{rC}-85473$ viruses, mice were challenged intra-nasally with $1 \times 10^{6} \mathrm{TCID}_{50}$ of WT rC-85473 
HMPV virus (50\% lethal dose). Mice immunized with OptiMEM were used as negative control. Viral titers and histopathological scores were evaluated at five days post-challenge as previously described. Prior to immunization/infection and 21 days after challenge, blood samples were taken to evaluate the neutralizing antibodies against the recombinant virus (rC-85473) or WT patient-derived homologous C-85473 and heterologous CAN98-75 strains. Reciprocal neutralizing antibody titers were determined by end-point dilution assay, as described [7].

To quantify pulmonary inflammatory cytokine/chemokine levels in HMPV-immunized challenged mice, we euthanized mice and harvested lungs on days one and five post-challenge. Lungs were homogenized in D-PBS containing protease inhibitors to perform the cytokines quantification using a commercial multiplex mouse cytokine bead assay (Bio-Plex Pro Mouse Cytokine 23-plex Assay, Bio-Rad, Hercules, CA, USA) according to the manufacturer's instructions. Results were analyzed with the Luminex system (QIAGEN).

In order to analyze lung-infiltrating immune cells, mice were deeply anesthetized and perfused intracardially with D-PBS without $\mathrm{Ca}^{2+}$ and $\mathrm{Mg}^{2+}$ on days one and five post-challenge. Lungs were collected, digested with Liberase TL and processed to recover living leukocytes, as described [34]. Then, cells were incubated on ice for $40 \mathrm{~min}$ with a pool of antibodies (anti-CD45, anti-Ly6G, anti-CD11b, anti-CD170/Siglec-F, anti-Ly6C, anti-CD11c, anti-F4/80, anti-B220, anti-CD3ع, anti-CD4 and anti-CD8a, purchased from BD) to discriminate cell populations. The count numbers of total pulmonary leukocytes (CD45+), neutrophils (LyG6+), macrophages (SiglecF+, F4/80+), lymphocytes T (CD3ع+) CD4+, CD8+ and lymphocytes B (B220+) were measured by flow cytometry from whole living cells. Number of cells were determined with Precision Count Beads ${ }^{\mathrm{TM}}$ (BioLegend, San Diego, CA, USA). Data acquisition and analyses were performed by a BD LSRII flow cytometer and the BD FACSDiva software.

Animal studies were approved by the SFR Biosciences Ethics Committee (CECCAPP C015 Rhône-Alpes, protocol ENS_2017_019) according to European ethical guidelines 2010/63/UE on animal experimentation and by the Animal Protection Committee of the Quebec University Health Centre (Protocol CPAC 2017-140-2) according to Canadian Council guidelines on Animal Care.

\subsection{Statistical Analysis}

Two-way ANOVAs with Dunnett post-tests were used to compare data of $\Delta S H$ and $\Delta G H M P V$ to their corresponding WT virus. Statistical analyses were performed using GraphPad Prism7.

\section{Results}

\subsection{In Vitro Characteristics of $\triangle G$ - and $\triangle S H-H M P V$ Recombinant Viruses Differ Depending on the Viral Strain Background}

Based on our previous studies [29,30], we successfully generated by reverse genetics different GFP-expressing HMPV recombinant viruses derived from the A1/C-85473 strain (rC-85473, $\Delta \mathrm{G}-\mathrm{C}-85473$, $\Delta$ SH-C-85473) and the B2/CAN98-75 strain (rCAN98-75, $\Delta$ G-CAN98-75 and $\triangle$ SH-CAN98-75) (Figure 1A). Rescued recombinant viruses were firstly assessed for their replicative capacity in LLC-MK2 cells over a seven-day period (Figure 1B,C). While rCAN98-75 virus peaked at $8.95 \times 10^{5}$ $\mathrm{TCID}_{50} / \mathrm{mL}$ at $4 \mathrm{dpi}, \triangle \mathrm{SH}$-CAN98-75 virus showed reduced replication as early as $2 \mathrm{dpi}$, with a $24 \mathrm{~h}$ delay to reach peak titer $\left(1.95 \times 10^{5} \mathrm{TCID}_{50} / \mathrm{mL}\right)$ (Figure $\left.1 \mathrm{~B}\right)$. A significantly more attenuated phenotype was observed with the $\triangle$ G-CAN98-75 virus, for which the highest viral titer measured $\left(5.72 \times 10^{4}\right.$ $\mathrm{TCID}_{50} / \mathrm{ml}$ at $7 \mathrm{dpi}$ ) was delayed and $1.2 \log 10$ lower than that of the WT (Figure 1B). This differential replication among the three CAN98-75-based recombinant viruses was also illustrated by representative fluorescent microscopy images of infected LLC-MK2 cells at $3 \mathrm{dpi}$, notably considering the extent of viral spread and GFP positive cells (Figure 1D). On the contrary, no such important differences in replication properties were observed between the two deleted C-85473-derived recombinant viruses and their WT counterpart (Figure 1C). Peak viral titers of approximately $1 \times 10^{5} \mathrm{TCID} \mathrm{D}_{50} / \mathrm{mL}$ for both the C-85473-WT and $\Delta$ SH-C-85473 viruses, or a peak of $4.22 \times 10^{4} \mathrm{TCID}_{50} / \mathrm{mL}$ for the $\Delta \mathrm{G}-\mathrm{C}-85473$ virus were 
reached by 4 dpi (Figure 1C). According to previous studies with the viral C-85473 background [29,30], fluorescence microscopy showed that $\triangle \mathrm{SH}-\mathrm{C}-85473$ and $\Delta \mathrm{G}-\mathrm{C}-85473$ viruses harbored high viral spread and hyperfusogenic phenotypes, comparable to the WT rC-85473 (Figure 1D).

Considering the different phenotypes of rHMPV virus derived from the A1/C-85473 and B2/CAN98-75 strains and the "attachment" role attributed to the G protein, we further evaluated the specific impact of the $\mathrm{G}$ and $\mathrm{SH}$ gene deletions on the binding and the entry of the rHMPV to LLC-MK2 cells (Figure 2). While the rCAN98-75 virus showed progressive binding kinetics, reaching a maximum of $68 \%$ GFP-positive cells after $3 \mathrm{~h}$ of adsorption, the $\triangle \mathrm{SH}$-CAN98-75 virus showed faster binding in the first hour, yet achieving a maximal plateau of $47 \%$ by $2 \mathrm{~h}$ (Figure 2A). Not surprisingly, the deletion of the $\mathrm{G}$ protein significantly hampered the binding capacity of the $\Delta \mathrm{G}-\mathrm{CAN} 98-75$ virus, with a mean of $\sim 10 \%$ GFP-positive cells all throughout the experiment (Figure $2 \mathrm{~A}$ ). In contrast, and as observed for the replicative capacities, the binding ability of the C-85473-derived viruses was not significantly hampered at $3 \mathrm{~h}$ by the gene deletions: $57 \%$ for $\Delta \mathrm{SH}$ - and $54 \%$ for $\Delta \mathrm{G}-\mathrm{C}-85473$ versus $43 \%$ for the WT rC-85473 (Figure 2B).

A

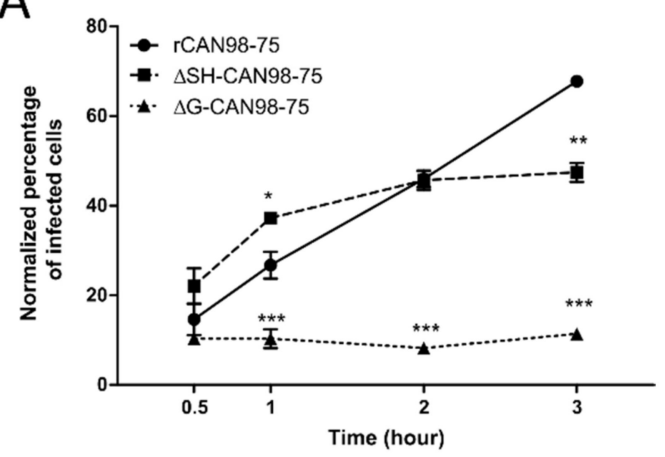

C

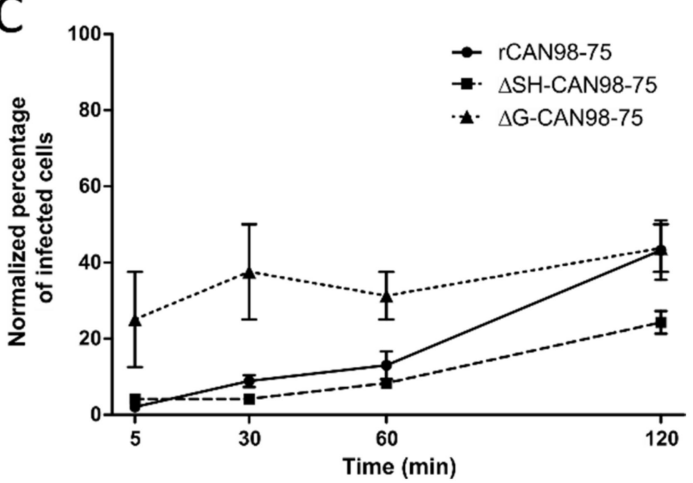

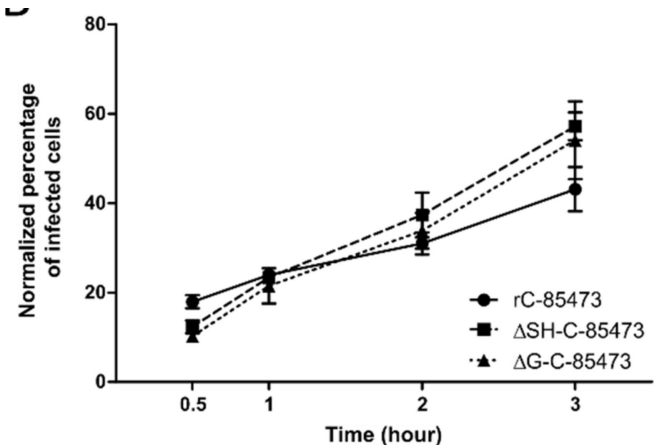

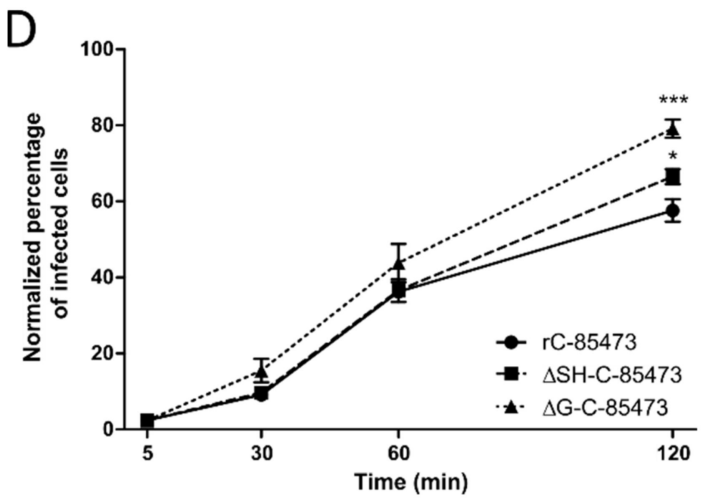

Figure 2. Binding and entry kinetics of $\mathrm{WT}, \triangle \mathrm{SH}$ - or $\triangle \mathrm{G}$ - rHMPV viruses in LLC-MK2 cells. Binding kinetics of (A) rCAN98-75-derived viruses and (B) rC-85473-derived viruses or entry kinetics of (C) rCAN98-75-derived viruses and (D) rC-85473-derived viruses in LLC-MK2 cells were measured by flow cytometry as described in Materials and Methods. Mean values represented triplicates in two independent experiments. ${ }^{*} p<0.05,{ }^{* *} p<0.01,{ }^{* * *} p<0.001$ when comparing each $\Delta \mathrm{SH} / \Delta \mathrm{G}$ virus to its WT counterpart using repeated measures two-way ANOVA.

Regarding cell entry kinetics, the $\triangle \mathrm{SH}-\mathrm{CAN98-75}$ virus seemed to enter LLC-MK2 cells slower than its WT counterpart and the $\triangle$ G-CAN98-75 virus, with $24 \%$ of $\Delta$ SH-CAN98-75-infected cells after $120 \mathrm{~min}$ compared to $43 \%$ for WT and $\Delta \mathrm{G}$-CAN98-75 viruses (Figure 2C). Conversely, the three rC-85473-derived viruses showed rather rapid cell entry kinetics with more than $36 \%$ of infected cells after $60 \mathrm{~min}$. Interestingly, both $\Delta \mathrm{SH}$ - and $\Delta \mathrm{G}-\mathrm{C}-85473$ viruses showed higher entry properties compared to their WT counterpart after 120 min with $66 \%, 79 \%$ and $57 \%$ of infected cells, respectively (Figure 2D). 
Altogether, our in vitro results on virus replication, cell binding and entry kinetics, suggested that $\mathrm{G}$ and $\mathrm{SH}$ deletions had strong differential impact on HMPV phenotypes depending on the viral background, hence highlighting a strain-dependent role of the viral surface proteins.

\section{2. $\Delta G$ - and $\Delta S H$-Viruses Harbor Different Replicative Properties in Reconstituted Human Airway Epithelium}

We further investigated the properties of $\Delta \mathrm{G}$ - and $\Delta \mathrm{SH}$-viruses by using reconstituted human airway epithelium (HAE) as a more physiological model of respiratory infection. Indeed, we previously showed that this model is permissive to HMPV infection and globally mimics the in vivo host respiratory epithelium response to such infection [37]. In line with these results, we observed that both rCAN98-75 and rC-85473-derived viruses are also able to infect, replicate and spread within the HAE (Figure 3).
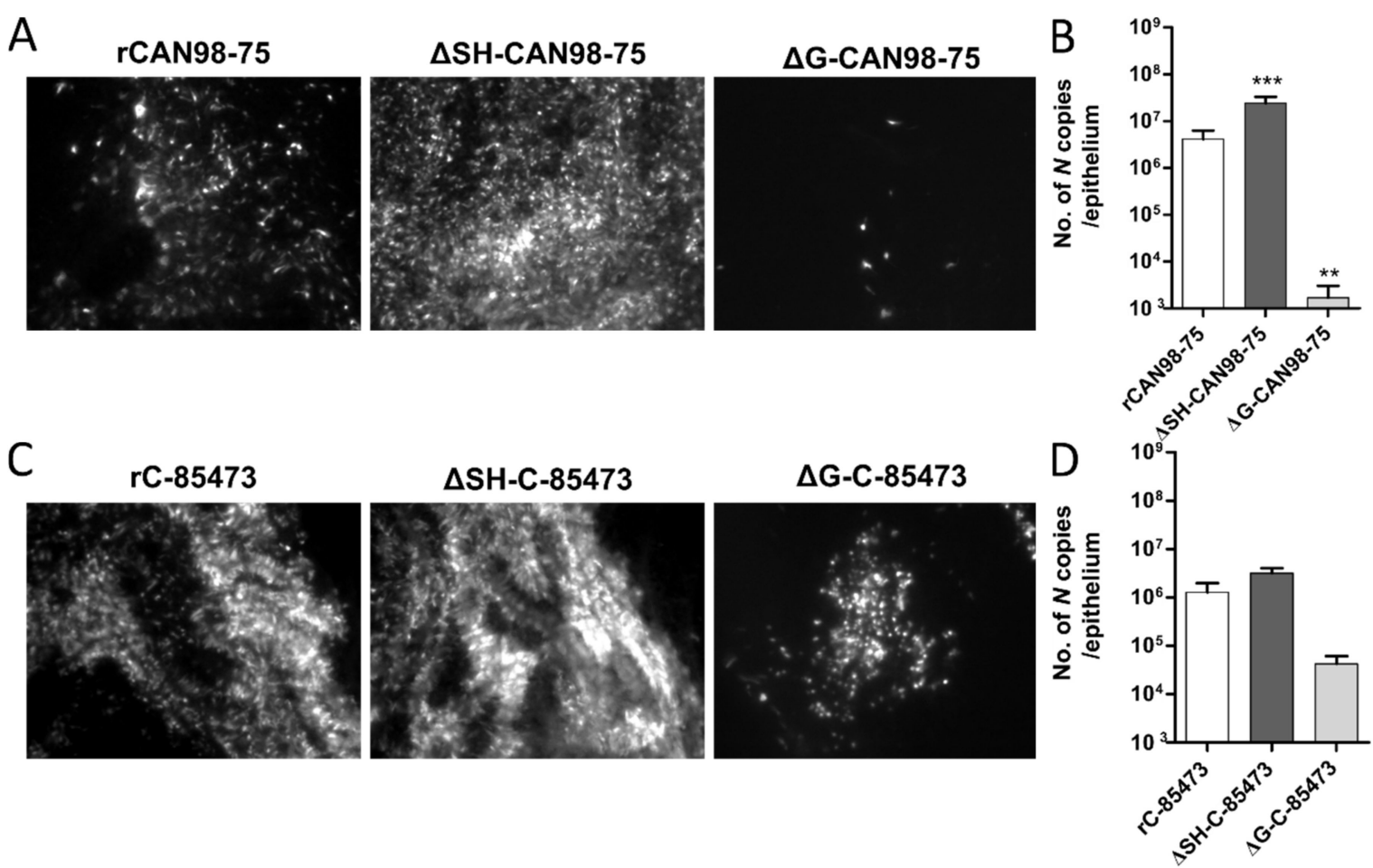

Figure 3. Recombinant HMPV viruses differed in infectivity and viral growth in reconstituted human airway epithelium (HAE). MucilAir ${ }^{\mathrm{TM}}$ epithelium from healthy donors were infected with the different rHMPV strains at a MOI of 0.1 . At $5 \mathrm{dpi}$, the viral spread in infected ciliated cells was monitored by fluorescence microscopy (images at 10× magnification) and the quantity of viral genome was measured by specific RT-qPCR against the $N$ viral gene from epithelium lysates, respectively (A) and (B) for rCAN98-75-derived viruses or (C) and (D) for rC-85473-derived viruses. Genome quantifications are shown as means \pm SD and represent experimental triplicates. ${ }^{* *} p<0.01,{ }^{* * *} p<0.001$ when comparing each $\Delta \mathrm{SH} / \Delta \mathrm{G}$ virus to its WT counterpart using repeated measures two-way ANOVA.

Based on the GFP expression pattern within the infected HAE at 5 dpi, we observed that the $\triangle$ SH-CAN98-75 spread more efficiently than its WT counterpart, at the difference of the $\Delta$ G-CAN98-75 virus, which appeared dramatically impaired (Figure 3A). These results were confirmed by the quantification of $N$ gene copies number within the infected epithelium. In line with the fluorescent microscopy observations, the viral quantifications at $5 \mathrm{dpi}$ indicated a significant six-fold higher viral

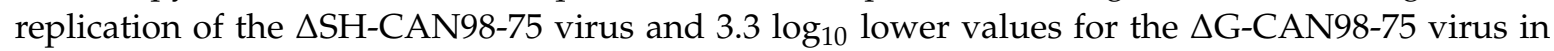
comparison to the WT CAN98-75 virus (Figure 3B). At the difference, the $\triangle \mathrm{SH}-\mathrm{C}-85473$ virus acted similarly to its WT counterpart, considering both spread pattern and viral replication within the HAE 
model (Figure 3C,D). In addition, the spread of the $\Delta \mathrm{G}-\mathrm{C}-85473$ virus seemed to be more affected in HAE model than in LLC-MK2 monolayer (Figure 3C) even though its replication diminished slightly in comparison to the WT rC-85473 virus, considering the 30-fold decrease of the number of $N$ gene copies (Figure 3D).

These results indicate that $r H M P V$ harbored different strain-dependent replicative properties in the HAE model (Figure 3) compared to the LLC-MK2 model (Figure 1). In the CAN98-75 viral background, the SH deletion significantly enhanced the viral replication and spread in HAE, whereas it caused a deleterious delay of replication in LLC-MK2 cells. In addition, the G deletion appeared to attenuate excessively the viral replication in HAE, in line with results in LLC-MK2 model. In contrast, rC-85473 viruses showed similar characteristics in both HAE and LLC-MK2 models, including comparable replication phenotypes between the WT virus and its derived deleted viruses, and especially the $\Delta \mathrm{SH}-\mathrm{C}-85473$ virus.

Altogether, considering the characteristics of the rC-85473-derived viruses in LLC-MK2 and HAE models, we focused on this viral backbone to further investigate in vivo functional impact of SH- and G-deletions and evaluate their potential in the development of LAV candidates.

\subsection{Immunization with Deleted-C-85473 Viruses Reduces HMPV Disease Severity in Challenged BALB/c Mice}

We therefore infected mice intra-nasally with $5 \times 10^{5} \mathrm{TCID}_{50}$ of either $\Delta \mathrm{G}-\mathrm{C}-85473$ or $\Delta \mathrm{SH}-\mathrm{C}-85473$ viruses, the equivalent non-lethal dose inoculum needed to induce a significant $(>10 \%)$ weight loss with the WT rC-85473 virus at 7 dpi (Figure 4A). Similar to the mock (non-infected) group and in contrast with the WT rC-85473, neither weight loss nor clinical signs were observed in the $\triangle \mathrm{G}-\mathrm{C}-85473$ and $\Delta \mathrm{SH}$-C-85473-infected groups during the 14-day follow-up. In contrast, lung viral titers at $5 \mathrm{dpi}$ were comparable between WT and deleted viruses, as determined by both cell culture and molecular methods (Figure 4B,C). In agreement with the weight curves, lower histopathological scores were recorded for both $\Delta$ G-C-85473 and $\Delta$ SH-C-85473-infected mice compared to the WT group (1.8 and 2.4 versus 5.3 , respectively), particularly owing to significant reductions in interstitial, perivascular and/or intra-alveolar inflammation (Figure $4 \mathrm{D}$ ).

We then evaluated the capacity of $\Delta \mathrm{SH}$ - and $\Delta \mathrm{G}-\mathrm{C}-85473$ attenuated viruses to protect mice from a lethal viral challenge. Upon viral challenge with $1 \times 10^{6} \mathrm{TCID}_{50}$ of $\mathrm{rC}-85473$ virus, mock-immunized mice showed significant (50\%) HMPV-associated mortality, starting on day five post-challenge and spanning until day eight post-challenge, with mean weight loss of $11 \%$ (peak after seven days) (Figure 5A). Conversely, both $\Delta \mathrm{SH}$ - and $\Delta \mathrm{G}-\mathrm{C}-85473$-immunized mice groups, as well as control rC-85473-immunized mice, were completely protected from HMPV-associated mortality induced by viral challenge and showed mean maximum weight losses of $3 \%-4 \%$ of their initial weight (peak at day two post-challenge) (Figure 5A,B).

Similarly, to the rC-85473 WT virus, the protection induced by immunization with $\triangle \mathrm{G}-\mathrm{C}-85473$ and $\triangle \mathrm{SH}-\mathrm{C}-85473$ was associated with the induction of high neutralizing antibody titers at 21 days after challenge, particularly in the case of $\Delta \mathrm{SH}-\mathrm{C}-85473$ (Table 2). Importantly, neutralization assays also showed that induced antibody responses were effective in neutralizing WT patient-derived strains as well as the heterologous CAN98-75 HMPV B strain (Table 2). In line with these results, we were unable to recover HMPV viruses or detect viral genome from the lungs of any of the three different rHMPV-immunized groups on day five post-challenge (Table 2). However, we still recorded reduced but significant pulmonary inflammation in WT- and $\Delta \mathrm{G}-\mathrm{C}-85473$-immunized mice, compared to mock-immunized mice (scores of 7.5 and 7 versus 9.5, respectively), whereas $\Delta \mathrm{SH}$-C-85473-immunized mice had a much lower histopathological score of 2.5 (Figure 5C). Indeed, $\Delta$ SH-C-85473-immunized group showed reduced interstitial and perivascular inflammations and no bronchial and intra-alveolar inflammation (Figure 5C). In contrast to mock-immunized mice, none of the rHMPV-immunized groups developed pulmonary edema after viral challenge (Figure S1). 

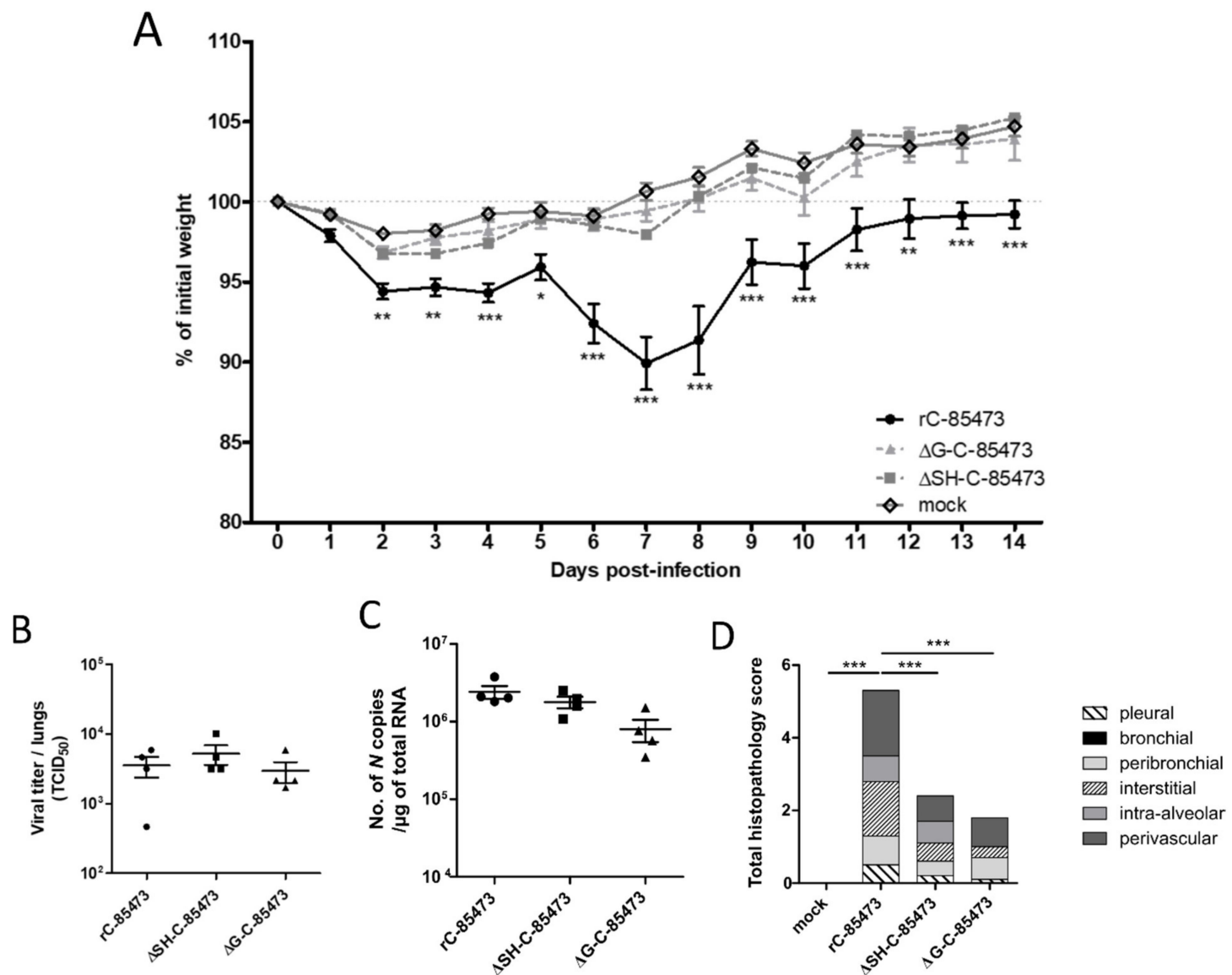

Figure 4. Weight loss, lung viral titers and histopathological scores of BALB/c mice infected with rC-85473-derived live-attenuated vaccines (LAV) candidates. BALB/c mice were intranasally infected with $5 \times 10^{5} \mathrm{TCID}_{50}$ of $\mathrm{rC}-85473 \mathrm{rHMPV}$ viruses (WT, $\triangle \mathrm{SH}$ and $\Delta \mathrm{G}$ ). (A) Weight loss was monitored during 14 days since infection $(n=16)$. At $5 \mathrm{dpi}$, mice were euthanized and lungs were harvested to measure viral titers by both $\mathrm{TCID}_{50}$ titration (B) and quantitative RT-PCR (C) $(n=4)$. (D) Cumulative histopathological scores (bronchial, peribronchial, perivascular, interstitial, pleural and intra-alveolar inflammation scores) of other infected mouse lungs were evaluated at $5 \mathrm{dpi}(n=5)$. Data are shown as means \pm SEM. ${ }^{*} p<0.05,{ }^{* *} p<0.01,{ }^{* * *} p<0.001$ when comparing each $\Delta \mathrm{SH} / \Delta \mathrm{G}$ virus to its WT counterpart using repeated measures two-way ANOVA.

Table 2. Immunogenicity and protective efficiency of HMPV C-85473-derived viruses in mice.

\begin{tabular}{|c|c|c|c|c|c|c|}
\hline \multirow[t]{2}{*}{ Imm. virus } & \multirow{2}{*}{$\begin{array}{l}\text { Imm. Inoculum } \\
\left(\log _{10} \text { TCID }^{50}\right)\end{array}$} & \multicolumn{3}{|c|}{$\begin{array}{l}\text { Reciprocal Neutralization Titer } 21 \text { Days } \\
\text { Post-Challenge against Different HMPV } \\
\text { Strains }(n=4)^{1}\end{array}$} & \multicolumn{2}{|c|}{$\begin{array}{l}\text { Challenge Virus Replication in } \\
\text { Lungs Five Days Post-Challenge } \\
\qquad(n=4)\end{array}$} \\
\hline & & rC-85473 & WT C-85473 & $\begin{array}{c}\text { WT } \\
\text { CAN98-75 }\end{array}$ & $\begin{array}{l}\text { Mice with } \\
\text { Detectable } \\
\text { Virus (\%) } \\
\end{array}$ & 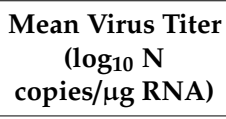 \\
\hline mock & & 10 & 7.5 & 12.5 & 100 & $4.8 \pm 4.3$ \\
\hline rC-85473 & 5.7 & $>160$ & 80 & 60 & 0 & $<1$ \\
\hline$\Delta$ SH-C-85473 & 5.7 & $>160$ & $>160$ & $>160$ & 0 & $<1$ \\
\hline$\Delta$ G-C-85473 & 5.7 & $>160$ & 80 & 70 & 0 & $<1$ \\
\hline
\end{tabular}

${ }^{1}$ Sera were tested for neutralization efficiency against $\mathrm{rC}-85473$ virus, which was the same recombinant virus used for infectious challenge; WT C-85473, as homologous A1 virus; and WT CAN98-75, as heterologous B2 strain. Two biological replicates per group were tested. The "naïve" status of mice was confirmed by neutralizing antibody dosage of sera harvested one day before intranasal immunization (reciprocal titer $<5$ ). Imm. = immunization. 


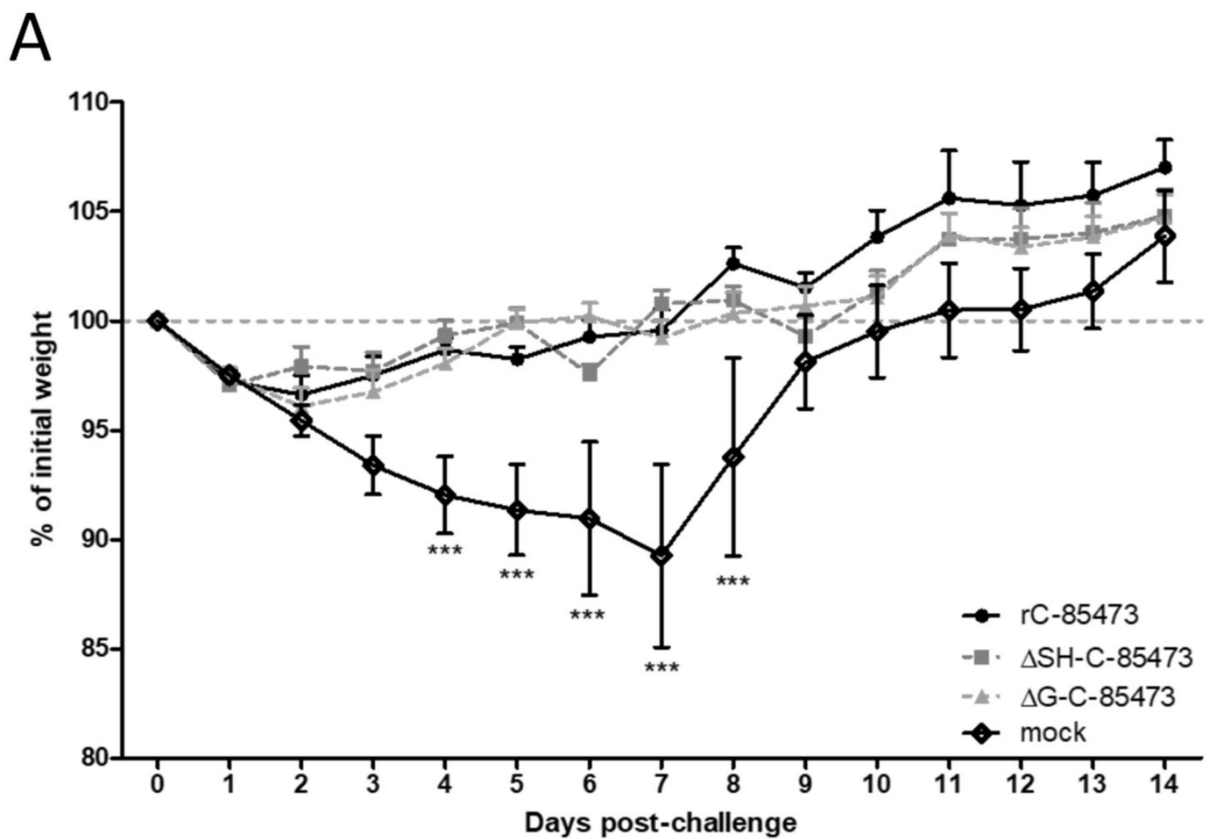

B

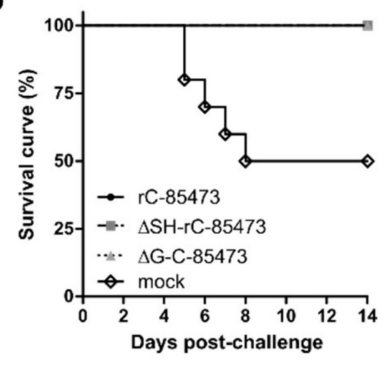

C

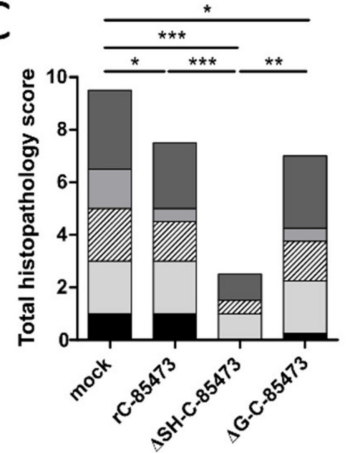

$\triangle \nabla$ pleural

bronchial

$\square$ peribronchial

שII interstitial

$\square$ intra-alveolar

$\square$ perivascular

Figure 5. Weight loss, survival and histopathological scores of HMPV-immunized mice after viral challenge. BALB/c mice were intranasally immunized with $5 \times 10^{5} \mathrm{TCID}_{50}$ of $\Delta \mathrm{SH}-\mathrm{C}-85473$, $\triangle \mathrm{G}-\mathrm{C}-85473$ or WT rC85473 viruses (immunization control), as previously described. Three weeks after immunization, animals $(n=16)$ were inoculated with $1 \times 10^{6} \mathrm{TCID}_{50}\left(\mathrm{LD}_{50}\right)$ of rC-85473 (viral challenge). (A) Weight loss and (B) mortality were monitored during 14 days after the viral challenge $(n=10)$. (C) Cumulative histopathological scores (bronchial, peribronchial, perivascular, interstitial, pleural and intra-alveolar inflammation scores) of infected mouse lungs were evaluated on day five post challenge $(n=2)$ while pulmonary viral titers were measured by RT-qPCR $(n=4$, Table 2$)$. Data are shown as means \pm SEM. ${ }^{*} p<0.05,{ }^{* *} p<0.01,{ }^{* * *} p<0.001$ when comparing each $\Delta \mathrm{SH} / \Delta \mathrm{G}$ virus to its WT counterpart using repeated measures two-way ANOVA.

To further characterize the immune response after viral challenge of the rHMPV-immunized mice, we characterized the production of pulmonary cytokines/chemokines and the subsequent infiltration of different immune cell populations into the lungs. As soon as one day after the challenge, we measured high expression levels of cytokines, corresponding to an acute response to high dose of viral challenge, as it is the case for RANTES $(19,000 \mathrm{pg} / \mathrm{mL}$, Figure 6A). Interestingly, higher levels of several cytokines/chemokines (IL-10, IL-6, G-CSF, TNF- $\alpha$ ) were measured in the lungs of $\Delta S H$-immunized mice in comparison with WT and $\Delta \mathrm{G}$-immunized groups (Figure $6 \mathrm{~A}$ ). In accordance with the absence of detectable virus (Table 2) and the decreased histopathological scores (Figure 5C), the level of most of the measured cytokines lowered five days post-challenge (Figure 6A). In addition, we observed an important recruitment of leukocyte populations in rHMPV-immunized groups from day one after challenge, which persisted for at least five days later (Figure 6B). Of note, the $\Delta S H$-immunized group 
showed significant enhanced infiltration of leukocytes in lungs five days post-challenge, particularly $\mathrm{T}$ CD4+, T CD8+ and B cell populations (Figure 6B).

A
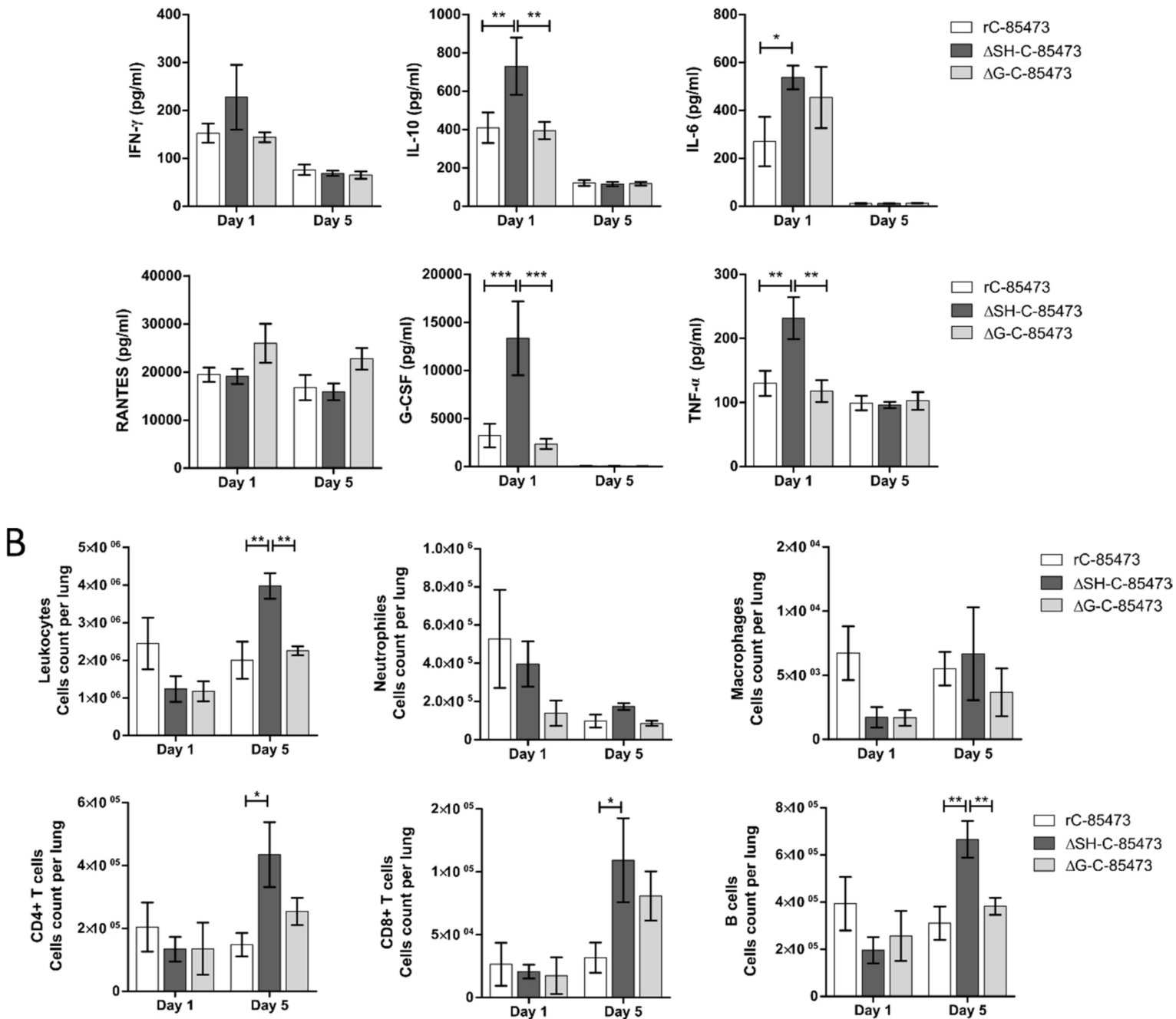

Figure 6. HMPV-immunized mice showed distinct cytokine/chemokine and immune cell infiltration profiles through time after viral challenge. BALB/c mice were intranasally immunized with 5 $\times 10^{5} \mathrm{TCID}_{50}$ of $\Delta \mathrm{SH}-\mathrm{C}-85473, \Delta \mathrm{G}-\mathrm{C}-85473$ or WT rC85473 viruses (immunization control), as previously described. Three weeks after immunization, animals were inoculated with $1 \times 10^{6}$ $\mathrm{TCID}_{50}\left(\mathrm{LD}_{50}\right)$ of rC-85473 (viral challenge). (A) Pulmonary inflammatory cytokine/chemokine levels in HMPV-immunized challenged mice were determined from lung homogenates on days one and five post-challenge, using a multiplex bead-based assay. Six cytokines/chemokines (IFN- $\gamma$, IL-10, IL-6, RANTES, G-CSF, TNF- $\alpha$ ) were selected considering both their detection levels and significance in HMPV-related disease. (B) Immune cell infiltration in lung homogenates was evaluated by flow cytometry on days one and five post challenge. ${ }^{*} p<0.05 ;{ }^{* *} p<0.01 ;{ }^{* *} p<0.001$ comparing each group using repeated measures two-way ANOVA.

Overall, our results suggested that deleted $\mathrm{rC}-85473$ viruses harbored distinct but attenuated and protective properties in the BALB/c model against a lethal HMPV viral challenge, together with reduced disease severity, weaker inflammatory responses and a balanced stimulation of the immune response, especially in the case of the $\Delta \mathrm{SH}-\mathrm{C}-85473$ virus. 


\section{Discussion}

Despite the necessity to develop vaccination strategies to prevent ARTI, neither FDA-approved vaccine nor specific antiviral against HMPV are currently available [38,39]. Considering the major burden of this virus in infants and young children, HMPV live-attenuated vaccines offer interesting properties to protect this specific population [8]. In that regard, while the first and only phase I clinical trial based on human-to-avian HMPV P substitution was non-conclusive [40], attenuation approaches based on gene deletion showed promising results in animals $[27,41]$. Nevertheless, previous studies on HMPV LAV were mainly restricted to the A2/CAN97-83 strain and did not take into account the genetic variability of HMPV viruses between and within subgroups, especially regarding the poorly conserved $\mathrm{G}$ and SH glycoproteins [42,43]. In fact, the limited knowledge on HMPV virulence factors and their putative roles still hampers the development of efficient therapeutic and prophylactic strategies against severe HMPV disease. In this study, we sought to address the problem of the impact of viral background on the differential effect of $\mathrm{G}$ and $\mathrm{SH}$ deletions by using two patient-derived HMPV strains, A1/C-85473 and B2/CAN98-75. We demonstrated that G- or SH-deleted A1/C-85473 viruses had unchanged replicative capacity in vitro compared to their WT counterpart (Figure 1), in line with a previous study advocating the putative "accessory role" of these two gene-products [27]. However, we observed that viral replication in LLC-MK2 cells was significantly decreased when G and, to a lesser extent $\mathrm{SH}$, were deleted from the B2/CAN98-75 virus (Figure 1). Such a distinct replication phenotype between $A$ and B viruses (A1/C-85473 and A2/CAN97-83 vs. B2/CAN98-75) suggests that the HMPV genetic background might influence the impact of gene deletions on viral fitness. This is of particular importance if we consider efficient production yield (i.e., comparable to that of the WT virus) as a major requirement for the development of a LAV candidate.

We also previously showed that C-85473 and CAN98-75 strains induce very different fusogenic phenotypes in vitro and pathogenicity in vivo, thanks to the specific characteristics of their respective F glycoproteins $[29,30]$. Besides its major role in viral fusion, the F protein may also retain importance for viral binding and entry into cell $[17,20,21]$. In this way, the C-85473 virus appeared to be less dependent on the $G$ protein to perform virus-to-cell binding than the CAN98-75 virus (Figure 2). It seems therefore possible that the lack of the $G$ protein could be compensated by the hyperfusogenic activity of the C-85473 F protein. In our study, the differential profiles exhibited by the two strains strengthen this hypothesis, as illustrated by the enhanced entry kinetics of the rC-85473 virus in comparison to the rCAN98-75 virus, despite the improved capacity of the latter to bind LLC-MK2 cells (Figure 2). Alternatively, although its specific function is still debated, $\mathrm{SH}$ is presumed to be a putative cofactor of some F proteins and therefore it could participate in the viral entry [26]. In this way, $\mathrm{SH}$ deletion could lead to mild viral attenuation in vitro, as reported for the $\triangle \mathrm{SH}-\mathrm{CAN} 98-75$ virus in Figure 1.

Contrasting with the LLC-MK2 model, the replication and spread of both $\Delta \mathrm{G}$ viruses was more limited in the HAE model, whereas the $\triangle \mathrm{SH}$ viruses showed efficient infectivity, notably in the case of the $\triangle \mathrm{SH}-\mathrm{CAN98-75}$ virus (Figure 3). Such divergent phenotypes between deleted viruses was previously shown with HRSV, for which the G protein differently contributes to virus-cell binding depending on both the cell lines and the virus strains studied [36]. In light of our results, we therefore propose that the stratified nature and surface receptor configuration of the physiological HAE model, combined with the presence of cilia and mucus, lead to a more limiting environment for effective infection with a G-deleted HMPV virus. Taken together, our data show for the first time the importance of HMPV background and experimental models which must be considered in the study of G and SH protein functions.

Based on their specific characteristics in the LLC-MK2 and HAE models, we focused on the two deleted $(\Delta S H$ and $\Delta G$ ) viruses issued from the C-85473 strain for further investigation in BALB/C mice. At the difference of other small animal models previously used, the murine model allows the monitoring of weight loss, lung viral replication/inflammation and other clinical signs during the time course of HMPV infection [44]. In our study, the $\triangle \mathrm{SH}-\mathrm{C}-85473$ and $\Delta \mathrm{G}-\mathrm{C}-85473$ viruses replicated 
in mice lungs similarly to their WT counterpart at 5 dpi while inducing no weight loss or mortality and lesser tissue inflammation (Figure 4). Accordingly, we recently showed that the SH deletion in the C-85473 backbone limits the virus-induced activation of NLRP3-inflammasome both in vitro and in vivo, and subsequently reduces inflammation and pathogenicity in HMPV infected mice [34].

Moreover, immunization with $\Delta$ SH-C-85473 and $\Delta \mathrm{G}-\mathrm{C}-85473$ fully protected mice against viral challenge with rC-85473 (Figure 5, Table 2). Remarkably, the post-challenge antibody response induced in both vaccinated groups was also effective against a heterologous HMPV B strain (Table 2), contrary to what was observed for the mock-immunized yet challenged group. Evaluation of the real cross-protection potential of immunization with $\Delta$ SH-C-85473 and $\Delta$ G-C-85473 candidates is needed. Additionally, $\triangle$ SH-C-85473-immunized mice showed a distinct pulmonary cytokine/chemokine profile after viral challenge, with a significant increasing expression of several HMPV-response related markers compared to the WT and $\Delta \mathrm{G}-\mathrm{C}-85473$ immunized groups (Figure $6 \mathrm{~A}$ ). Interestingly, a high expression of IL-10 cytokine [45] and G-CSF chemokine, which were reported as T-cell activators [46], was concomitant with an enhanced recruitment of immune cells (T CD4+, T CD8+, B cells) in lungs of $\Delta \mathrm{SH}-\mathrm{C}-85473$-immunized mice at five days post-challenge (Figure 6B). Moreover, such a production of anti-inflammatory cytokine/chemokine counteracts the observed increased production of TNF- $\alpha$ and IL-6 pro-inflammatory (Figure 6A).

\section{Conclusions}

Given the significant clinical burden of HMPV $[1,2]$ and some pitfalls in the development of vaccine candidates $[7,40,47]$, we considered it important to reexamine the gene deletion-based attenuation approach $[6,27,41]$. Our study provides compelling evidence on the so far overlooked variable function of HMPV G and SH proteins relative to the viral background, the differential effects resulting from their deletion and the potential implications for the design of LAV candidates. In line with this rationale, the attenuated and broad protective properties displayed by the $\triangle \mathrm{SH}-\mathrm{C}-85473$-engineered virus, yet not inducing enhanced disease markers, in addition to its efficient replication in cell-based system, make it a promising live-attenuated HMPV vaccine candidate.

\section{Patents}

The authors declare a patent submission (FR1856801, PCT FR2019/051759) about HMPV LAV candidates.

Supplementary Materials: The following are available online at http://www.mdpi.com/2076-393X/7/4/164/s1, Figure S1: HMPV-immunized mice showed significant differences in histopathology five days after viral challenge.

Author Contributions: Conceptualization, J.D., M.R.-C. and G.B.; methodology, J.D. and M.-H.C.; validation, J.D. and M.- È.H.; formal analysis, J.D. and C.N.d.L.; investigation, J.D., B.P., O.U., M.-C.V., J.C., A.T., T.J., A.P., S.L. and C.C.; resources, J.C. and A.T.; writing—original draft preparation, J.D.; writing—review and editing, A.P., O.T., M.È.H., M.R.-C. and G.B.; visualization, J.D. and C.N.d.L.; supervision, B.L., G.B. and M.R.-C.; project administration, J.D., G.B. and M.R.-C; funding acquisition, G.B. and M.R.-C.

Funding: This study was supported by a grant from Canadian Institutes of Health Research (No. 273261) to GB and Universite Claude Bernard Lyon 1, Lyon, France. Julia Dubois received the support of the Région Auvergne-Rhône-Alpes (grant CMIRA ExploRA'DOC) and of the Consulat Général de France à Québec (Programme Frontenac).

Acknowledgments: We thank the microscopy and flow cytometry services of the Plateforme of Bio-Imagerie of CRI in Québec and the Centre d'Imagerie Quantitative Lyon-Est (CIQLE) in Lyon, as well as the animal care services of the Plateau de Biologie Expérimentale de la Souris in Lyon.

Conflicts of Interest: The authors declare no conflict of interest. The funders had no role in the design of the study; in the collection, analyses, or interpretation of data; in the writing of the manuscript, or in the decision to publish the results. 


\section{References}

1. Van den Hoogen, B.G.; Herfst, S.; Sprong, L.; Cane, P.A.; Forleo-Neto, E.; de Swart, R.L.; Osterhaus, A.D.; Fouchier, R.A. Antigenic and genetic variability of human metapneumoviruses. Emerg. Infect. Dis. 2004, 10, 658-666. [CrossRef]

2. Feuillet, F.; Lina, B.; Rosa-Calatrava, M.; Boivin, G. Ten years of human metapneumovirus research. J. Clin. Virol. 2012, 53, 97-105. [CrossRef] [PubMed]

3. Papenburg, J.; Boivin, G. The distinguishing features of human metapneumovirus and respiratory syncytial virus. Rev. Med. Virol. 2010, 20, 245-260. [CrossRef] [PubMed]

4. Rima, B.; Collins, P.; Easton, A.; Fouchier, R.; Kurath, G.; Lamb, R.A.; Lee, B.; Maisner, A.; Rota, P.; Wang, L.; et al. ICTV Virus Taxonomy Profile: Pneumoviridae. J. Gen. Virol. 2017, 98, 2912-2913. [CrossRef] [PubMed]

5. Mazur, N.I.; Higgins, D.; Nunes, M.C.; Melero, J.A.; Langedijk, A.C.; Horsley, N.; Buchholz, U.J.; Openshaw, P.J.; McLellan, J.S.; Englund, J.A.; et al. The respiratory syncytial virus vaccine landscape: lessons from the graveyard and promising candidates. Lancet Infect. Dis. 2018, 18, e295-e311. [CrossRef]

6. Marquez-Escobar, V.A. Current developments and prospects on human metapneumovirus vaccines. Expert Rev. Vaccines 2017, 16, 419-431. [CrossRef]

7. Hamelin, M.E.; Couture, C.; Sackett, M.K.; Boivin, G. Enhanced lung disease and $\mathrm{Th}_{2}$ response following human metapneumovirus infection in mice immunized with the inactivated virus. J. Gen. Virol. 2007, 88, 3391-3400. [CrossRef]

8. Karron, R.A.; Buchholz, U.J.; Collins, P.L. Live-attenuated respiratory syncytial virus vaccines. Curr Top Microbiol. Immunol. 2013, 372, 259-284.

9. Papenburg, J.; Carbonneau, J.; Isabel, S.; Bergeron, M.G.; Williams, J.V.; De Serres, G.; Hamelin, M.E.; Boivin, G. Genetic diversity and molecular evolution of the major human metapneumovirus surface glycoproteins over a decade. J. Clin. Virol. 2013, 58,541-547. [CrossRef]

10. Huck, B.; Scharf, G.; Neumann-Haefelin, D.; Puppe, W.; Weigl, J.; Falcone, V. Novel human metapneumovirus sublineage. Emerg. Infect. Dis. 2006, 12, 147-150. [CrossRef]

11. Peret, T.C.; Boivin, G.; Li, Y.; Couillard, M.; Humphrey, C.; Osterhaus, A.D.; Erdman, D.D.; Anderson, L.J. Characterization of human metapneumoviruses isolated from patients in North America. J. Infect. Dis. 2002, 185, 1660-1663. [CrossRef] [PubMed]

12. Hamelin, M.E.; Abed, Y.; Boivin, G. Human metapneumovirus: a new player among respiratory viruses. Clin. Infect. Dis. 2004, 38, 983-990. [CrossRef] [PubMed]

13. Nidaira, M.; Taira, K.; Hamabata, H.; Kawaki, T.; Gushi, K.; Mahoe, Y.; Maeshiro, N.; Azama, Y.; Okano, S.; Kyan, H.; et al. Molecular epidemiology of human metapneumovirus from 2009 to 2011 in Okinawa, Japan. Jpn. J. Infect. Dis. 2012, 65, 337-340. [CrossRef] [PubMed]

14. Biacchesi, S.; Skiadopoulos, M.H.; Boivin, G.; Hanson, C.T.; Murphy, B.R.; Collins, P.L.; Buchholz, U.J. Genetic diversity between human metapneumovirus subgroups. Virology 2003, 315, 1-9. [CrossRef]

15. Van den Hoogen, B.G.; Bestebroer, T.M.; Osterhaus, A.D.; Fouchier, R.A. Analysis of the genomic sequence of a human metapneumovirus. Virology 2002, 295, 119-132. [CrossRef] [PubMed]

16. Skiadopoulos, M.H.; Biacchesi, S.; Buchholz, U.J.; Amaro-Carambot, E.; Surman, S.R.; Collins, P.L.; Murphy, B.R. Individual contributions of the human metapneumovirus F, G, and SH surface glycoproteins to the induction of neutralizing antibodies and protective immunity. Virology 2006, 345, 492-501. [CrossRef] [PubMed]

17. Cox, R.G.; Williams, J.V. Breaking in: Human metapneumovirus fusion and entry. Viruses 2013, 5, $192-210$. [CrossRef]

18. Adamson, P.; Thammawat, S.; Muchondo, G.; Sadlon, T.; Gordon, D. Diversity in glycosaminoglycan binding amongst hMPV G protein lineages. Viruses 2012, 4, 3785-3803. [CrossRef]

19. Cox, R.G.; Livesay, S.B.; Johnson, M.; Ohi, M.D.; Williams, J.V. The human metapneumovirus fusion protein mediates entry via an interaction with RGD-binding integrins. J. Virol. 2012, 86, 12148-12160. [CrossRef]

20. Chang, A.; Masante, C.; Buchholz, U.J.; Dutch, R.E. Human metapneumovirus (HMPV) binding and infection are mediated by interactions between the HMPV fusion protein and heparan sulfate. J. Virol. 2012, 86, 3230-3243. [CrossRef]

21. Cseke, G.; Maginnis, M.S.; Cox, R.G.; Tollefson, S.J.; Podsiad, A.B.; Wright, D.W.; Dermody, T.S.; Williams, J.V. Integrin $\alpha v \beta 1$ promotes infection by human metapneumovirus. PNAS 2009, 106, 1566-1571. [CrossRef] [PubMed] 
22. Bao, X.; Liu, T.; Shan, Y.; Li, K.; Garofalo, R.P.; Casola, A. Human metapneumovirus glycoprotein G inhibits innate immune responses. PLoS Pathog. 2008, 4, e1000077. [CrossRef] [PubMed]

23. Kolli, D.; Bao, X.; Liu, T.; Hong, C.; Wang, T.; Garofalo, R.P.; Casola, A. Human metapneumovirus glycoprotein G inhibits TLR4-dependent signaling in monocyte-derived dendritic cells. J. Immunol. 2011, 187, 47-54. [CrossRef] [PubMed]

24. Bao, X.; Kolli, D.; Ren, J.; Liu, T.; Garofalo, R.P.; Casola, A. Human Metapneumovirus Glycoprotein G Disrupts Mitochondrial Signaling in Airway Epithelial Cells. PLoS ONE 2013, 8, e62568. [CrossRef] [PubMed]

25. Bao, X.; Kolli, D.; Liu, T.; Shan, Y.; Garofalo, R.P.; Casola, A. Human metapneumovirus small hydrophobic protein inhibits NF-KB transcriptional activity. J. Virol. 2008, 82, 8224-8229. [CrossRef] [PubMed]

26. Masante, C.; El Najjar, F.; Chang, A.; Jones, A.; Moncman, C.L.; Dutch, R.E. The human metapneumovirus small hydrophobic protein has properties consistent with those of a viroporin and can modulate viral fusogenic activity. J. Virol. 2014, 88, 6423-6433. [CrossRef]

27. Biacchesi, S.; Skiadopoulos, M.H.; Yang, L.; Lamirande, E.W.; Tran, K.C.; Murphy, B.R.; Collins, P.L.; Buchholz, U.J. Recombinant human Metapneumovirus lacking the small hydrophobic SH and/or attachment G glycoprotein: Deletion of $G$ yields a promising vaccine candidate. J. Virol. 2004, 78, 12877-12887. [CrossRef]

28. Biacchesi, S.; Skiadopoulos, M.H.; Tran, K.C.; Murphy, B.R.; Collins, P.L.; Buchholz, U.J. Recovery of human metapneumovirus from cDNA: Optimization of growth in vitro and expression of additional genes. Virology 2004, 321, 247-259. [CrossRef]

29. Aerts, L.; Cavanagh, M.H.; Dubois, J.; Carbonneau, J.; Rheaume, C.; Lavigne, S.; Couture, C.; Hamelin, M.E.; Boivin, G. Effect of in vitro syncytium formation on the severity of human metapneumovirus disease in a murine model. PLoS ONE 2015, 10, e0120283. [CrossRef]

30. Dubois, J.; Cavanagh, M.H.; Terrier, O.; Hamelin, M.E.; Lina, B.; Shi, R.; Rosa-Calatrava, M.; Boivin, G. Mutations in the fusion protein heptad repeat domains of human metapneumovirus impact on the formation of syncytia. J. Gen. Virol. 2017, 98, 1174-1180. [CrossRef]

31. Nao, N.; Sato, K.; Yamagishi, J.; Tahara, M.; Nakatsu, Y.; Seki, F.; Katoh, H.; Ohnuma, A.; Shirogane, Y.; Hayashi, M.; et al. Consensus and variations in cell line specificity among human metapneumovirus strains. PLoS ONE 2019, 14, e0215822. [CrossRef] [PubMed]

32. Mas, V.; Herfst, S.; Osterhaus, A.D.; Fouchier, R.A.; Melero, J.A. Residues of the human metapneumovirus fusion $(\mathrm{F})$ protein critical for its strain-related fusion phenotype: Implications for the virus replication cycle. J. Virol. 2011, 85, 12650-12661. [CrossRef]

33. Herfst, S.; Mas, V.; Ver, L.S.; Wierda, R.J.; Osterhaus, A.D.; Fouchier, R.A.; Melero, J.A. Low-pH-induced membrane fusion mediated by human metapneumovirus $\mathrm{F}$ protein is a rare, strain-dependent phenomenon. J. Virol. 2008, 82, 8891-8895. [CrossRef]

34. Le, V.B.; Dubois, J.; Couture, C.; Cavanagh, M.H.; Uyar, O.; Pizzorno, A.; Rosa-Calatrava, M.; Hamelin, M.E.; Boivin, G. Human metapneumovirus activates NOD-like receptor protein 3 inflammasome via its small hydrophobic protein which plays a detrimental role during infection in mice. PLoS Pathog. 2019, 15, e1007689. [CrossRef] [PubMed]

35. Hamelin, M.E.; Yim, K.; Kuhn, K.H.; Cragin, R.P.; Boukhvalova, M.; Blanco, J.C.; Prince, G.A.; Boivin, G. Pathogenesis of human metapneumovirus lung infection in BALB/c mice and cotton rats. J. Virol. 2005, 79, 8894-8903. [CrossRef] [PubMed]

36. Meng, J.; Hotard, A.L.; Currier, M.G.; Lee, S.; Stobart, C.C.; Moore, M.L. Respiratory Syncytial Virus Attachment Glycoprotein Contribution to Infection Depends on the Specific Fusion Protein. J. Virol. 2015, 90, 245-253. [CrossRef]

37. Nicolas de Lamballerie, C.; Pizzorno, A.; Dubois, J.; Julien, T.; Padey, B.; Bouveret, M.; Traversier, A.; Legras-Lachuer, C.; Lina, B.; Boivin, G.; et al. Characterization of cellular transcriptomic signatures induced by different respiratory viruses in human reconstituted airway epithelia. Sci. Rep. 2019, 9, 11493. [CrossRef]

38. Mayor, S. Acute respiratory infections are world's third leading cause of death. BMJ 2010, 341, c6360. [CrossRef]

39. Vekemans, J.; Moorthy, V.; Giersing, B.; Friede, M.; Hombach, J.; Arora, N.; Modjarrad, K.; Smith, P.G.; Karron, R.; Graham, B.; et al. Respiratory syncytial virus vaccine research and development: World Health Organization technological roadmap and preferred product characteristics. Vaccine 2018. [CrossRef]

40. Karron, R.A.; San Mateo, J.; Wanionek, K.; Collins, P.L.; Buchholz, U.J. Evaluation of a Live Attenuated Human Metapneumovirus Vaccine in Adults and Children. J. Pediatr. Infect. Dis. Soc. 2017, 7, 86-89. [CrossRef] 
41. Biacchesi, S.; Pham, Q.N.; Skiadopoulos, M.H.; Murphy, B.R.; Collins, P.L.; Buchholz, U.J. Infection of nonhuman primates with recombinant human metapneumovirus lacking the $\mathrm{SH}, \mathrm{G}$, or M2-2 protein categorizes each as a nonessential accessory protein and identifies vaccine candidates. J. Virol. 2005, 79, 12608-12613. [CrossRef] [PubMed]

42. Bastien, N.; Liu, L.; Ward, D.; Taylor, T.; Li, Y. Genetic variability of the G glycoprotein gene of human metapneumovirus. J. Clin. Microbiol. 2004, 42, 3532-3537. [CrossRef] [PubMed]

43. Piyaratna, R.; Tollefson, S.J.; Williams, J.V. Genomic analysis of four human metapneumovirus prototypes. Virus Res. 2011, 160, 200-205. [CrossRef] [PubMed]

44. Schildgen, O.; Simon, A.; Williams, J. Animal models for human metapneumovirus (HMPV) infections. Veterinary research 2007, 38, 117-126. [CrossRef] [PubMed]

45. Sun, L.; Cornell, T.T.; LeVine, A.; Berlin, A.A.; Hinkovska-Galcheva, V.; Fleszar, A.J.; Lukacs, N.W.; Shanley, T.P. Dual role of interleukin-10 in the regulation of respiratory syncitial virus (RSV)-induced lung inflammation. Clin. Exp. Immunol. 2013, 172, 263-279. [CrossRef] [PubMed]

46. Malashchenko, V.V.; Meniailo, M.E.; Shmarov, V.A.; Gazatova, N.D.; Melashchenko, O.B.; Goncharov, A.G.; Seledtsova, G.V.; Seledtsov, V.I. Direct anti-inflammatory effects of granulocyte colony-stimulating factor (G-CSF) on activation and functional properties of human T cell subpopulations in vitro. Cell. Immunol. 2018, 325, 23-32. [CrossRef]

47. Kim, H.W.; Canchola, J.G.; Brandt, C.D.; Pyles, G.; Chanock, R.M.; Jensen, K.; Parrott, R.H. Respiratory syncytial virus disease in infants despite prior administration of antigenic inactivated vaccine. Am. J. Epidemiol. 1969, 89, 422-434. [CrossRef]

(C) 2019 by the authors. Licensee MDPI, Basel, Switzerland. This article is an open access article distributed under the terms and conditions of the Creative Commons Attribution (CC BY) license (http://creativecommons.org/licenses/by/4.0/). 